\title{
SYSTEMATIC ENVIRONMENTAL INFLUENCES AND VARIANCES DUE TO DIRECT AND MATERNAL EFFECTS AND TRENDS FOR YEARLING WEIGHT IN CATTLE
}

\author{
${ }^{1}$ ASSAN, N. and ${ }^{2}$ NYONI K. \\ ${ }^{1}$ Zimbabwe Open University, Matebeleland South Region, Post Office Box 346, Gwanda, Zimbabwe. \\ ${ }^{2}$ Matopos Research Station, Post Office Mail Bag 5137, Bulawayo, Zimbabwe.
}

Corresponding Author: Assan, N. Zimbabwe Open University, Matebeleland South Region, Box 346, Gwanda, Zimbabwe. Email: neverssan@yahoo.com Phone: 263084 2965/6

\begin{abstract}
Pedigree yearling records from 1021 local Tuli calves born at Matopos Research Station were analyzed for non genetic factors, genetic parameters and trends on the yearling weight. It was found that sire, year of birth, sex of calf, age of dam had significant effect $(p<0.01)$ on all growth trait. The inconsistency of literature estimates indicated the importance of estimation of environmental factors that affect yearling weight within specific experimental herds and environment. Model incorporating both direct and maternal additive genetic effect, covariance and correlations of direct-maternal and permanent environmental maternal effects was adopted for the study. Direct and maternal heritability estimates of $0.18 \pm 0.001$ and $0.04 \pm 0.001$ were observed, respectively. Direct-maternal genetic correlation was low and positive, $0.07 \pm 0.012$. The regression of average direct breeding values on year was almost zero and the regression of average maternal breeding values on year $0.03 \mathrm{~kg} / \mathrm{yr}$. Correction of environmental effects was necessary to increase accuracy for selection of yearling weight in local Tuli cattle. Maternal genetic effects should be included in a model of covariance components estimation at 12 months of age.
\end{abstract}

Keywords: Non genetic, Direct, Maternal trends, Yearling weight, Growth traits, Tuli cattle

\section{INTRODUCTION}

Yearling weight is the second most important trait after fertility and is of value in selecting both heifer and bull for replacement of the breeding herd (Sibanda, 1999) and its importance is also derived from its positive genetic correlation with mature weight which is the common interest of the farmers (Norris et al., 2004). Definition and quantification of systematic environmental influences in domestic animals is a prerequisite to successful conduct of performance recording schemes (Bosso et al., 2009). Adjustment of growth records for such factors provides a basis for the objective selection of animals and the design of breeding programs (Holland and Odde, 1992; Fields and Sand, 1994) and the knowledge of the extent of their effects on weight traits enable development of effective management systems for increased beef production.

Plans to implement genetic improvement programmes which utilize adapted genotypes of indigenous cattle in Sub Saharan Africa is the only way to secure sustainable beef production meant for the local population. Indigenous livestock breeds have always played an important role in the lives of people of Sub Saharan Africa (Bosso et al., 2009), however information on genetic parameters which are population specific are scanty for Sanga cattle herds indigenous to East, Central and Southern Africa (Beffa, 2005). Such information on the nature and magnitude of population parameters(i.e. variance components and heritabilities) for these cattle herds are needed for effective designing of breeding programmes and to estimate breeding values for traits of relevance to beef producers (Intaratham et al., 2008).

Evaluation of genetic and environmental trends is crucial in the tropics, where environmental differences in climatic conditions, particularly rainfall, are high (Haile-Mariam and Philipson, 1995). Genetic trends are very useful tool to evaluate the results of the genetic improvement programme (Bosso et al., 2009). Annual trends for weight traits should be monitored over time to check the validity of the predictions made and to investigate direction of genetic change and whether the selection strategies implemented could reach a selection limit or have unexpected other effects. The objectives of this study were: (1) to establish the effects of non-genetic factors on yearling weight in local Tuli cattle (2) to 
estimate direct and maternal effects for yearling weight in the local Tuli cattle (3) to evaluate genetic trends for yearling weight in the local Tuli cattle of Zimbabwe.

\section{MATERIALS AND METHODS}

Environment: Matopos Research Station (20 0 23' $\mathrm{S}, 31030^{\prime} \mathrm{E}$ ) is situated $30 \mathrm{~km}$ South West of Bulawayo in Zimbabwe. The stations altitude is low $(800 \mathrm{~m})$ and it experiences low erratic rainfall $(<450)$ per annum (Homann et al., 2007). Very high summer temperatures, maximum and minimum mean temperatures of hottest months are $21.6{ }^{\circ} \mathrm{C}$ and 11.4 ${ }^{\circ} \mathrm{C}$ respectively. Possibility of severe droughts (Hagreveas et al., 2004). The most common type of vegetation is sweet veld with comparatively high nutritional value as browsing crop (Ncube, 2005) and annual grass species (Hlatswayo, 2008). If managed well the range lands should be able to meet the nutritional requirements of goats and other livestock (van Rooyen et al., 2007). However, significant proportion of the rangeland are now degraded, resulting in low biomass (Hlatswayo, 2008) and thus limited feed resource of poor quality particularly during the dry season (Day et al., 2003). Gambiza and Nyama (2000) gave detailed description of the climate and vegetation type. The development and management of the herd has been described by Ward et al. (1978).

Non-Genetic Factors Analysis: Data on yearling weight were obtained from Matopos Research Station, Bulawayo, Zimbabwe, between 1988 to 1997. The data included a total of 1021 pedigree progeny records from 42 sires and 420 dams of the local Tuli cattle (Table 1). The General Linear Model (GLM) procedure of the Statistical Analysis System (SAS) (1999 - 2000) was used to establish the significance of the non-genetic factors. The linear statistical model fitted was: Yijklm $=\mathrm{u}+\mathrm{Gi}+\mathrm{Pj}+$ $\mathrm{Sk}+\mathrm{Al}+$ Eijklm, where: Yijklm is the Ith observation of ith sire, jth year and kth sex; $u$ is the overall population mean; $\mathrm{Gi}$ is the random effect of ith sire $\operatorname{NID}(0, \sigma 2 \mathrm{~s}) ; \mathrm{Pj}$ is the fixed effect of jth year of birth $(j=1988,1989, \ldots . . ., 1997) ; S k$ is the fixed effect of kth sex of calf ( $k=$ male, female); $A l$ is the fixed effect of Ith age of dam $(I=1,2 \ldots 15)$; eijklm is the random error associated with each observation assumed to be NID $(0, \sigma 2 e)$.

Animal Model: An animal model was applied to estimate variance components and genetic parameters using ASREML methodology (Gilmour et al., 2000). In matrix notation the univariate mixed linear model used was of the maternal form: $Y=X b$ $+\mathrm{Zu}+\mathrm{Wm}+\mathrm{Spe}+\mathrm{e}$, where $\mathrm{Y}=$ vector of yearling weight; $b=$ vector of year of birth, sex and age of dam; $\mathrm{u}=$ vector of random animal effects; $\mathrm{m}=$ vector of random maternal (indirect) genetic effects; pe $=$ vector of random permanent environmental maternal effects of dam; $\mathrm{e}=$ vector of random residual effects; $\mathrm{X}, \mathrm{Z}, \mathrm{W}$ and $\mathrm{S}$ are incidence matrices relating records to fixed, animal, maternal genetic and permanent environmental maternal effects respectively.

Genetic trends were estimated as the regression of the mean predicted direct and maternal breeding values on year of birth. Environmental trends were directly obtained from the estimates of the fixed effects solutions of year of birth and phenotypic trends from the annual least squares means.

Table 1: Summary statistics of the data sets for yearling weight in local Tuli cattle of Zimbabwe

\begin{tabular}{lc}
\hline Component & Recorded values \\
\hline Records & 1021 \\
Animals & 1553 \\
Base parents & 462 \\
Sires & 42 \\
Dams & 420 \\
Mean & 172.25 \\
SD & 28.46 \\
\hline
\end{tabular}

$S D=$ standard deviation

\section{RESULTS AND DISCUSSION}

Differences between sire, year of birth, sex and age of dam were highly significant $(p<0.001)$ for yearling weight (Tables 2 and 3 ) and conform to reports in literature (Bosso et al., 2009). The significance for sire effect for yearling weight did not declined even this could be probable sire influence carry over effects unlike the maternal influence which tend to decline with progressed age of the animal. Post-natal influence that has been estimated is the sum of the effects of the 'true' post natal maternal environment and probably also the carried over effect of the prenatal maternal which would have declined by age of 1 year. Much of the sire estimated effects were much of genetic potential than environmental for yearling weight. Bull calves were $11 \%$ heavier than heifers at 1 year weight. Covariance component and genetic parameters for yearling weight are presented in Tables 3 and 4. The sum of total additive genetic variance for yearling weight in local Tuli cattle was 192.77 and variance component for maternal permanent environmental maternal genetic variance for yearling weight were less than $1 \%$ in local Tuli. 
Table 2: Analysis of variance for yearling weight in local Tuli cattle of Zimbabwe

\begin{tabular}{lcc}
\hline Factor & df & SS \\
\hline Sire & 1 & $498.90^{* *}$ \\
Sex & 1 & $72357.26^{* * *}$ \\
Year of birth & 8 & $4381.71^{* * *}$ \\
Age & 12 & $2116.65^{* * *}$ \\
Error & & 541.29 \\
\hline${ }^{*} p<(0.05),{ }^{* *} p<(0.01),{ }^{* * *} p<(0.001)$ &
\end{tabular}

Table 3: Least squares means for yearling weight in local Tuli cattle of Zimbabwe

\begin{tabular}{lc}
\hline Effects & $\begin{array}{c}\text { Least squares mean } \\
\text { Sex } \\
\text { Male }\end{array}$ \\
Female & $180.89 \pm 1.73$ \\
& $161.29 \pm 1.59$ \\
$\mathbf{3}$ & $169.83 \pm 2.40$ \\
$\mathbf{4}$ & $174.37 \pm 2.54$ \\
$\mathbf{5}$ & $181.42 \pm 2.27$ \\
$\mathbf{6}$ & $180.16 \pm 2.37$ \\
$\mathbf{7}$ & $180.84 \pm 2.79$ \\
$\mathbf{8}$ & $185.10 \pm 2.58$ \\
$\mathbf{9}$ & $176.93 \pm 2.75$ \\
$\mathbf{1 0}$ & $175.96 \pm 3.47$ \\
$\mathbf{1 1}$ & $173.48 \pm 3.58$ \\
$\mathbf{1 2}$ & $165.85 \pm 3.83$ \\
$\mathbf{1 3}$ & $160.51 \pm 4.27$ \\
$\mathbf{1 4}$ & $146.89 \pm 4.49$ \\
$\mathbf{1 5}$ & $152.82 \pm 8.07$ \\
& Year of birth \\
$\mathbf{1 9 8 8}$ & $170.77 \pm 2.55$ \\
$\mathbf{1 9 8 9}$ & $163.95 \pm 2.60$ \\
$\mathbf{1 9 9 0}$ & $158.01 \pm 3.33$ \\
$\mathbf{1 9 9 1}$ & $170.02 \pm 3.13$ \\
$\mathbf{1 9 9 2}$ & $172.27 \pm 5.07$ \\
$\mathbf{1 9 9 3}$ & $161.46 \pm 4.99$ \\
$\mathbf{1 9 9 4}$ & $166.26 \pm 5.24$ \\
$\mathbf{1 9 9 5}$ & $189.16 \pm 6.20$ \\
$\mathbf{1 9 9 6}$ & $176.69 \pm 5.99$ \\
$\mathbf{1 9 9 7}$ & $162.67 \pm 5.78$ \\
\hline & \\
\end{tabular}

The residual variance components accounted for over $70 \%$ of the phenotypic variance and were the largest component of the phenotypic variance of the trait. The magnitude of total genetic variance probably reflects large sampling covariances among estimates in the local cattle breeds. Direct and maternal genetic effects and their covariances have not been previously established as important for yearling weight in local Tuli in Zimbabwe. Direct heritability estimates observed was $0.18 \pm 0.001$, and were comparable with those reported elsewhere (Abassa et al., 1989; Swalve, 1993; Mac Neil et al., 1998; Mercadante et al., 2003). Higher estimates of direct heritability of 0.25 and 0.30 have been reported in cattle (Mc Neil, 2003; Norris et al., 2004). Direct heritability estimates on the upper range have also been reported worldwide for yearling weights; 0.38
(Splan et al., 1998), 0.27 (Meyer, 1994), 0.48 (Groeneveld et al., 1998) and 3.6 (Ferreira et al., 1999). In a study on the difference in yearling weights of cattle due to sexes, Van Vleck and Cundiff (1998) reported direct heritability of 0.55 and 0.49 for females and males respectively, while in another study Khan and Akhtar (1995) reported 0.26 and 0.71 as direct heritabilities for females and males respectively. Mohiudin (1993) in a comprehensive review found a wide variety of estimates of heritability for female yearling weight. Range of 0.16 to 0.71 with an average estimate of 0.48 was much higher than the estimate found in this study. However, the 0.18 heritability for female yearling weight was within the reported range (Mohiudin, 1993). Lower estimates of direct heritability for yearling weight than in the present study have been reported in cattle e.g. 0.14 (Lee et al., 2000) and 0.09 (Lubout et al., 1990). The methods used in most of the studies which reported higher estimates of direct heritability in literature ignored maternal effects, which could have inflated the additive genetic variance and not always the residual variance (Meyer, 1992), increasing the estimates of heritability. Bosso et al. (2009) found an increasing trend in direct heritability birth weight $(0.40)>$ weaning weight (0.47) > weight at 15 months $(0.48)$ without accounting for maternal genetic effects. The presence of a maternal genetic effect in our model might have contributed to the low estimates of yearling weight.

The relatively high maternal components that explains $14 \%$ of the total variation indicates that this effect should be kept in the model of analysis even at the age of one year. The maternal heritability estimates for yearling weight were lower than direct heritability $(0.18$ vs. 0.14$)$. The maternal heritability estimates were low as compared to those observed in earlier reports in beef cattle (Swalve, 1993; Mercadante, et al., 1997; Mac Neil et al., 1998). The maternal heritability in this study is within the reported range (Meyer, 1992; Lee et al., 2000) in Australian beef cattle and Ferreira et al. (1999) using different statistical models. The magnitude of maternal effects indicates that maternal effects were important for yearling weight in this herd. Maternal effects on post weaning growth traits of beef cattle have been found in some breeds as for the local Tuli cattle (Koch et al., 1973; Alenda and Martin, 1987).

The maternal permanent environmental effects contributed less than $1 \%$ in the present study; elsewhere Wasike et al. (2000) observed a higher contribution of $4 \%$ in Boran cattle in Kenya, while Pico (2004) reported $3 \%$ maternal permanent environmental effects for yearling weight which was slightly higher than the 0.02 reported for Nelore 
cattle (Eler et al., 1992). Within the same range Meyer (1992) estimated for both the Australian Angus and Zebu crosses maternal permanent environmental effects of 0.03 . Five percents were reported for Hereford cattle (Meyer, 1992), Boran cattle (Hailemariam and Kassa-Mersh, 1995) and Gobra cattle of Senegal (Diop and Van Vleck, 1998).

The results in literature dealing with the genetic correlations between direct and maternal effects for yearling weight are mostly negative: for example, -0.50 for Gobra cattle of Senegal (Diop, 1997) and -0.48 for Herefords (Meyer, 1993). Directmaternal genetic correlations in the present study were low and positive, $0.07 \pm 0.01$. Positive genetic correlation of direct-maternal genetic correlation for yearling weight of $0.40 \pm 0.31,0.05 \pm 0.31$ and 0.64 \pm 0.37 in Pinzgauer, Gelbvieh and Red Poll cattle, respectively, and of 0.01 for Zebu crosses and 0.49 for Angus in Australia for yearling weight have been reported (Mackinnon et al., 1991; Meyer, 1992). The positive genetic correlation of direct-maternal genetic effect for yearling weight is an indication that there is no antagonistic tendency which could retard selection progress (Meyer, 1993). However, we can not rule out that the positive direct-maternal genetic correlation could probably be the result of smaller data sets used in this study. The estimates of direct and maternal genetic correlation could not be ignored taking into account the proportion of maternal to direct genetic variance for yearling weight.

The total heritability and maternal acrossyear repeatability for dam performance were moderate and low. Use of total genetic effects on selection $\left(h^{2} t\right)$ (Table 5 ) for yearling weight would optimize genetic progress in local Tuli cattle due to the positive covariance between direct and maternal effects.

Table 4: Estimates of genetic and environmental variances and covariances for yearling weight in local Tuli cattle of Zimbabwe

\begin{tabular}{ccccc}
\hline $\boldsymbol{\sigma}^{2} \mathbf{A}$ & $\boldsymbol{\sigma}^{2} \mathbf{M}$ & $\boldsymbol{\sigma}^{2} \mathbf{A M}$ & $\boldsymbol{\sigma}^{2} \mathbf{E}$ & $\boldsymbol{\sigma}^{2} \mathbf{P}$ \\
\hline 111.00 & 86.77 & 6.55 & 412.80 & 617.47 \\
\hline$\sigma^{2} A=$ direct & additive & genetic; & $\sigma^{2} M=$ maternal additive \\
genetic variance; $\sigma^{2} A M=$ direct and additive variance; $\sigma^{2} E$ \\
=error variance; $\sigma^{2} P=$ phenotypic variance = sum of \\
variance and covariance components
\end{tabular}

The direct and maternal trends yearling weights are depicted in Figures 1 and 2 respectively. The differences in average estimated breeding values for direct genetic effects showed that there was very little in terms of genetic gain was realized despite the moderate heritability of yearling weight. The regression of average direct breeding values on year of birth for YWT was almost zero and the regression of average maternal breeding values on year was $0.03 \mathrm{~kg} / \mathrm{yr}$. Yearling weight had a maximum average maternal breeding value in year 1993 of $0.29 \mathrm{~kg} / \mathrm{yr}$ and direct genetic gain remained constant around zero.

Table 5: Direct additive ( $\left.{ }^{2} A\right)$, maternal ( $\left.h^{2} M\right)$ and total $\left(h^{2} \mathrm{~T}\right)$ heritability estimates, standard errors (SE) and correlation between direct and maternal effects (rAM) for yearling weight in local Tuli cattle of Zimbabwe

\begin{tabular}{cccc}
\hline $\mathbf{h}^{\mathbf{2}} \mathbf{A}$ SE & $\mathbf{h}^{\mathbf{2}} \mathbf{M}$ SE & $\mathbf{h}^{\mathbf{2}} \mathbf{T}$ & rAM \\
\hline $0.18 \pm 0.001$ & $0.14 \pm 0.01$ & 0.27 & 0.07 \\
\hline
\end{tabular}

This was an indication that there was less or not much of correlated response in post weaning growth traits in the selection program. The trends in breeding values for both direct and maternal effects for yearling weight ( $0.00 \mathrm{vs}$. $0.03 \mathrm{~kg}$ per year) were modest when compared with an average of $2.65 \mathrm{~kg}$ per year reported by Mrode (1988) for yearling weight, when reviewing the results of selection experiments. The majority of the estimates of genetic trends reported by Mrode (1988) are from cattle breeds in temperate environments. Few studies have been reported on the improvement of genetic gain in N'Dama in Gambia by $0.17 \mathrm{~kg} / \mathrm{yr}$ (Boss et al., 2009) and Santa Getrudis in Brazil by $0.291 \mathrm{~kg} / \mathrm{yr}$ (Ferraz et al., 2000).

The present study is amongst other studies that report positive rate of improvement of yearling weight from harsh semi-arid tropical environment. In this herd, selection for yearling weight theoretically, considering a total heritability of 0.27 and phenotypic standard deviation of $31.69 \mathrm{~kg}$, and assuming an estimated average selection intensity of $(i=1.08)$ where $10 \%$ males $(\operatorname{Im}=1.755)$ and $75 \%$ females (If $=0.424)$ were retained for breeding, the generation interval calculated 5.3 years for males and 7.2 years for females, would give a genetic gain of more than $1.0 \mathrm{~kg}$ per year, if single trait individual selection was practiced. The genetic gain observed is less than 50 percent of what seems possible, even if regression of breeding values on year of birth is considered. There was no reason to expect low genetic gains in the study due to the low positive correlation of -0.07 between direct and maternal effects for yearling weight which showed an unantagonistic tendency which makes it possible to improve both effects simultaneously. Presume the low gains are a result of bulls in particular were not selected at all among those of born in some years, and those selected were not necessarily superior to their contemporaries because selection was based on 
their own performance and their parents unadjusted weaning weights.

Environmental conditions were improving during the study period as indicated by the significant positive trend (Figure 2). This partially suggests that selection on yearling weight may result into selection for genetic stability in cattle in harsh tropical environments, however the $R^{2}(0.47)$ from environmental values, as observed, was less likely to be expected under fluctuating climatic conditions and the effect that they have on availability and quality of grazing.

Conclusion: The inconsistency of published results on non genetic factors in cattle indicates the importance of quantifying the effects of environmental factors on yearling weight within specific herd and environment and failure to adjust for age of dam will result in selection biased against the progeny of younger dams with a resulting increase in generation interval and reduced selection intensity. Maternal genetic effects should be included in a model of covariance components estimation in local Tuli cattle raised in Zimbabwe even for traits measured at 12 months of age. Estimates of direct and maternal heritability for 12 months of age indicate that selection can be effective on population studied. Maternal genetic trends were significant and positive but very low for 12 months, inclusion of sire evaluation program may increase genetic progress in the herd. The results suggest that individual selection or mass selection based on 12 months weight should be effective due to a slight positive covariance component

\section{ACKNOWLEDGEMENT}

The authors would like to thank all staff involved in the management of the local Tuli conservation herd at Matopos Research Station over the years.

\section{REFERENCES}

ABASSA, K. P., WILCOX, C. J. and OLSON, T. A. (1989). Genetic aspects of growth in Gobra Zebu cattle. Revista Brasileira Genetica, 12: $795-801$.

ALENDA, R. and MARTIN, T. G. (1987). Genetic parameters and consequences of selection for growth traits in beef cattle herd selected for yearling weight. Journal of Animal Science, 64: $366-372$.

BEFFA, L. M. (2005). Genotype: Environment interaction in Afrikaner cattle. PhD Dissertation, University of The Free State, Bloemfontein, South Africa.
BOSSO, N. A., VAN DER WAAIJ, E. H., AGYEMANG, K. and VAN ARENDOK, J. A. M. (2009). Genetic parameters for growth traits in N'Dama cattle under tsetse challenge in the Gambia. Livestock Resources and Rural Development, 21(3): XXX - XXX.

DAY, K. A., MACLAURIN, G., DUBE, S., HLATSHWAYO, A. S. and TREVOR, C. (2003). Capturing the benefits of seasonal climate forecasts in agricultural management. Final Report for Australian Center for International Agricultural Research (ACIAR). June 2003, Sub Project 3, Grazing Systems in Zimbabwe, 67 pp.

DIOP, M. (1997). Design and analysis of open nucleus breeding systems for cattle in Senegal. PhD Thesis University of Nebraska. Lincoln. USA.

DIOP, M. and VAN VLECK, L. D. (1998). Estimates of genetic parameters for growth traits of Gobra cattle. Animal Science, 66: 349 - 355.

ELER, J. P., FERRAZ, J. B. S., LOBO, J. B. and JOSAKIAN, I. A. (1992). Genetic antagonism between growth and maternal ability in Nelore cattle. Journal of Animal Science, 70: $x x x-x x x$.

FERRAZ, J. B. S., ELER, J. P. and RIBEIRO, P. M. T. (2000). Genetic study of Santa Getrudis cattle in Brazil. Livestock Resources and Rural Development, 12(2): $130-137$.

FERREIRA, G. B., MACNEIL, M. D. and VAN VLECK, L. D. (1999). Variance components and breeding values for growth traits from different statistical models. Journal of Animal Science, 77: $2641-2650$.

FIELDS, M. J. and SANDS, R. S. (1994). Factors affecting calf crop. CRC Press, London.

GILMOUR, A. R., CULLIS, B. R., WELHAM, S. J. and THOMPSON, R. (2000). ASREML Reference Manual.

GROENEVELD, B., MOSTERT, E. and RUST, T. (1998). The covariance structure of growth traits in Afrikaner beef population. Livestock Production Science, 55: 99 - 107.

HAILE-MARIAM, M. and PHILIPSON, J. (1995). Estimates of genetic and environmental trends of growth traits in Boran cattle. Blackwell, Wissenschafts-Verlag, Berlin.

HOLLAND, M. D. and ODDE, K. G. (1992). Factors affecting calf birth weight - A Review. Theriogenology, 38: $769-\mathrm{xxx}$.

HOMANN, S., VAN ROOYEN, A. F., MOYO, T. and NENGOMAHSA, Z. (2007). Goat production and marketing: Baseline information for semi-arid Zimbabwe. International Crops Research Institute for the Semi-Arid Tropics. POBox 776, Bulawayo, Zimbabwe.

INTARATHAM, W., KOONAWOOTRITTRIRON, S., SOPANNARATH, P., GRASER, H. U. and TUMWASORN, S. (2008). Genetic parameters and annual trends for birth and weaning weights of a Northeastern Thai indigenous cattle line. Asian-Australian Journal of Animal Science, Vol Pages. 
KHAN, R. N. and AKHTAR, S. (1995). Estimates of genetic parameters of some growth traits in Jersey cattle. African Journal of Animal Science, 8(6): $567-570$.

KOCH, R. M. L., CUNDIFF, L. V., GREGORY, K. E. and DICKERSON, G. E. (1973). Genetic and phenotypic relation associated with preweaning and postweaning growth of Hereford bulls and heifers. Journal of Animal Science, 36: 235 - xxx.

LEE, J. W., CHOI, S. B, JUNG, Y. H, KEOWN, J. F. and VAN VLECK, L. D. (2000). Parameter estimates for direct and maternal genetic effects on yearling weight, eighteen-month and slaughter weights of Korean native cattle. Journal of Animal Science, 78: 1414 1421.

LUBOUT, P. C. and SWANEPOEL, F. C. J. (1999). Genetic parameters of Sanga cattle in developing areas. Pages $x x x-x x y$. In: Editor(s) Proceedings of the $4^{\text {th }}$ World Congress on Genetics Applied to Livestock Production, XIV Dairy Cattle Genetics and Breeding, Adaptation, Conservation. Edinburgh 23 - 27 July 1990 Edinburgh, United Kingdom.

MAC NEIL, M. D., URICK, J. J. and SNELLING, W. M. (1998). Comparison of selection by independent culling levels for below average birth weight and high yearling weight with mass selection for yearling weight in line 1 Hereford cattle. Journal of Animal Science, 76: 458 - 467.

MAC NEIL, M. D. (2003). Genetic evaluation of an index of birth weight and yearling weight to improve efficiency of beef production. Journal of Animal Science, 81: 2425 - 2433.

MACKINNON, M. J., MEYER, K. and HERTZEL, D. J. (1991). Genetic variation and covariation for growth, parasite resistance and heart tolerance in tropical cattle. Livestock Production Science, 27: $105-122$.

MERCANDANTE, M. E. Z. and LOBO, R. B. (1997). Estimates of covariance components and genetic parameters for growth traits due to direct and maternal effects in Nelore heifers. Revista Brasileira de Zootecnia., 26: 1124 1133.

MERCANDANTE, M. E. Z., PACKER, I. U., RAZOOK, A. G., CYRILLO, J. N. S. G. and FIGUEREDE, L. A. (2003). Direct and correlated responses to selection for yearling weight or reproductive performance of Nelore cows. Journal of Animal Science, 81: 376 - 384.

MEYER, K. (1992). Variance components due to direct and maternal effects for growth traits of Australian beef cattle. Livestock Production Science, 31:179- 204.

MEYER, K. (1993). Covariance matrices for growth traits of Australian polled Hereford cattle. Animal Production, 57: 37 - 45.

MEYER, K. (1994). Estimates of direct and maternal correlations among growth traits in
Australian beef cattle. Livestock Production Science, 38: 91 - 105.

MEYER, K., CARRICK, M. J. and DONNELLY, B. J. P. (1992). Estimates of covariance components for growth traits for the Wokalup single and multi-breed research herds. Pages 427 430. In: Editor(s) Proceedings of the Tenth Conference of the Australian Association for Animal Breeding and Genetics, Rockhampton.

MOHIUDDIN, G. (1993). Estimates of genetic and phenotypic parameters of some performance traits in beef cattle. Animal Breeding, 61: $495-522$.

MORRIS, C. A., BACKER, R L. and HUNTER, J. C. (1992). Correlated responses to selection for yearling or 18 month weight in Angus and Hereford cattle. Livestock Production Science, 30: $33-52$.

NCUBE, S. (2005). The role of proanthocyanidins and related flavonoids in the utilization of sorghum grain varieties as feed for ruminant in the semi arid areas of Zimbabwe. PhD Thesis, University of Zimbabwe, Mt Pleasant, Harare, Zimbabwe.

NORRIS, D., BANGA, C., BENYI, K. and SITHOLE, B. C. (2004). Estimation of genetic parameters and variance components for growth traits of Nguni cattle in Limpopo province South Africa. Tropical Animal Health and Production, 36(8): $801-806$.

RAZOOK, A. G., FIGUEIREDO, L. A., BONILHA NETO, L. M., TROVO, J. B. F.. PACKER, I. U., PACOLA, L. J., CYRILLO, J. N. S. G., RUGGIERI, A. C. and MERCANDANTE, M. E. Z. (1998). Selection for yearling weight in Nelore and Guzera zebu breeds: selection applied and response in 15 years of progeny. Pages 133 - 136. In: Editor(s) Proceedings of the $6^{\text {th }}$ World Congress of Genetics and Applied Livestock Production. Armidale, NSW, Australia.

SAS (1999-2000). Statistical Analysis System, Institute Inc, USA.

SHIN, O. Y., KIM, J. B., HAN, K. J. and PARK, Y. I. (1990). Estimation of genetic parameters for economic traits in Korean Native cattle (Hanwoo). Korean Journal of Animal Science, 32: 190 - 197.

SIBANDA, S. (1999). Animal Production and Health Management. Module 1 Beef Production: CASD301. Zimbabwe Open University.

SPLAN, R. K., CUNDIFF, L. V. and VAN VLECK, L. D. (998). Genetic parameters for sex-specific traits in beef cattle. Journal of Animal Science, 76: $2272-2278$.

SWALVE, H. H. (1993). Estimation of direct and maternal covariance components for growth traits in Australian Simmental beef cattle. Journal of Animal Breeding and Genetics, Vol Pages.

TAWONEZVI, H. P. R., BROWNLEE, J. W. L. and WARD, H. K. (1986). Studies on growth of Nkone cattle: Environmental influences on 
body mass. Zimbabwe Journal of Agricultural Research, 24: $17-29$.

TEOTIA, V. S., SINGH, H. and PRASAD, R. B. (1990). Genetic studies on growth and milk production traits in Sahiwal $x$ Holstein Friesian crossbreds. Indian Journal of Dairy Science, 43: $447-450$.

VAN ROOYEN, A. F., FREEMAN, A. MOYO, S. and ROHR BACK, D. (2007). Livestock Development in Southern Africa. Future Research and Investment Priorities. ICRISAT Bulawayo, Zimbabwe.

WARD, H. K., DAVISON, J., PRENTICE, A., TIFFIN, J. DE W., BROWNLEE, J. W. I., HARVEY, H. R., ARROWSMITH, S. P., BENNET, S., SAIRAI, J. N., DUBE,. I. A. and MOYO, G. (1978). Improvement of beef cattle productivity through crossbreeding. Annual Report. 1976/77. Division of Livestock and Pastures, Dept. of Research and Specialist Services, Harare.

WASIKE, C. B., INDETIE, D., OJANGO, J. M. K. and KAHI, A. K. (2009). Direct and maternal covariance components and genetic parameters for growth and reproductive traits in the Boran cattle in Kenya. Tropical Animal Health and Production, 41(5): 741 748.

WINDER, J. A., BRINKS, J. S, BOURDON, R. M. and GOLDEN, B. L. (1990). Genetic analysis of absolute growth measurements, relative growth rate and restricted selection indices in Red Angus cattle. Journal of Animal Science, 68: 330 - 336. 